\title{
Article \\ Gamification as a Strategy to Increase Motivation and Engagement in Higher Education Chemistry Students
}

\author{
Guillermo M. Chans ${ }^{1}$ (D) and May Portuguez Castro ${ }^{2, *(D)}$ \\ 1 School of Engineering and Sciences, Tecnologico de Monterrey, Av. Carlos Lazo 100, \\ Mexico City 01389, Mexico; guillermo.chans@tec.mx \\ 2 Institute for the Future of Education, Tecnologico de Monterrey, Monterrey 64849, Mexico \\ * Correspondence: may.portuguez@tec.mx
}

Citation: Chans, G.M.; Portuguez Castro, M. Gamification as a Strategy to Increase Motivation and Engagement in Higher Education Chemistry Students. Computers 2021, 10, 132. https://doi.org/10.3390/ computers10100132

Academic Editors: Ioana Andreea Stefan and Samir Garbaya

Received: 31 July 2021

Accepted: 11 October 2021

Published: 16 October 202

Publisher's Note: MDPI stays neutral with regard to jurisdictional claims in published maps and institutional affiliations.

Copyright: (c) 2021 by the authors. Licensee MDPI, Basel, Switzerland. This article is an open access article distributed under the terms and conditions of the Creative Commons Attribution (CC BY) license (https:/ / creativecommons.org/licenses/by/ $4.0 /)$.

\begin{abstract}
In the last year, educational experiences have become increasingly challenging due to teaching classes remotely. For this reason, it has been necessary to develop educational strategies that accompany the use of new technologies to maintain student interest. One of these methodologies is gamification, implemented in school environments more frequently due to the pandemic and whose impact on student motivation and engagement needs to be explored. The literature shows that student participation in these contexts should be increased when applying this methodology, where teachers can also provide greater support. This research proposes improving these aspects by developing a gamification strategy that can be easily replicated in other environments. This study was carried out for a chemistry course at a university in central Mexico. This proposal details the short-, medium-, and long-term bonuses which stimulated and motivated students and achieved specific objectives. We also present the quantitative results of a questionnaire applied to 48 engineering students to identify their perceptions of how gamification could increase motivation and engagement in learning the subject of chemistry. In addition, pre- and post-knowledge tests were applied to determine whether there were changes in the learning outcomes. The results indicated that gamification increased student motivation and engagement, improved attitudes, promoted actions such as keeping the camera on during lectures and regular attendance, and improved student grades. This study fills the need for planning strategies to help improve student motivation in online classes and proposes an instrument to measure the results. It can be helpful to those interested in applying or adapting it in other disciplines.
\end{abstract}

Keywords: gamification; motivation; engagement; higher education; educational innovation; professional education

\section{Introduction}

The training of science students is increasingly challenging, complicated by the recent pandemic which forced educational institutions to resort to distance learning to continue student education [1]. This situation was difficult for students to understand, so virtual environments had to be adequately prepared to maintain their attention and commitment. In many cases, the students were not ready to face this new reality. Thus, teaching strategies during the pandemic included tools for better understanding the topics presented within a wholly digital environment.

Digital pedagogies aim for personalized and adaptive learning in a virtual context; their new designs must create innovative teaching-learning environments which improve students' experiences and results $[2,3]$. These pedagogies include strategies which promote active learning, involving students in solving real-life problems [4].

\subsection{Gamification}

One of the learning strategies used in online learning is gamification, which has attracted a great deal of interest in recent decades due to its potential influence on improving 
user engagement and enjoyment [5]. Gamification is a method where different game strategies and mechanics are employed in non-game contexts to promote user engagement and motivation [6]. This methodology seeks to engage users in an interactive system that motivates them to participate in the process of a given activity $[7,8]$. The central idea is to take elements from games and implement them in real-world situations, often to motivate specific behaviors $[9,10]$, aiming to support and encourage the user toward the targeted behavior, such as a participation in learning activities [11].

Gamification is considered to be innovative and can be applied in a variety of contexts. According to the literature, there are different ways in which this tool can be adapted in the educational environment. One of the main fields that gamification can positively impact is online learning [12], where one of its benefits is to address problems such as the lack of student motivation. In the educational environment, there are different techniques associated with game design to improve interactions with students. These strategies allow students to develop curricular, social, and cognitive competencies [13] due to their potential to generate a feeling of empowerment to achieve tasks and work collaboratively, among other values related to games [14].

Previous studies viewed gamification as a didactic technique favoring students' professional skills, increasing the sense of community, improving how content is learned, and increasing engagement [15].

This finding was essential due to the need to create virtual learning spaces, so the contribution of this strategy was to foster interactions among users and improve motivation [16]. Gamification activities incentivized the user toward specific actions or behaviors [11]. They helped the learners' long-term engagement and persistence to attain the results of the learning activities. Although there are many studies on this topic, gamification still has excellent potential for further research, especially its impact on learner motivation.

Among the main gaming elements are points, badges, leaderboards (PBL) [13], awards, recognitions, achievement levels and respective feedback, which must be strategically used to achieve the intended interactivity and engagement with the problem, the content, and the target audience [17]. However, the game elements alone do not make people more motivated [18]. Principles must be applied to be successful in implementing gamification, [19] such as:

- Relatedness: refers to the need to be connected to others.

- Competence: the need to be effective and master a problem in a given environment.

- Autonomy: the need to be in control of one's own life.

We used these design principles in the proposal we developed, aiming to increase students' motivation toward the course in this study.

\subsection{Gamification in Science}

Gamification seeks to promote student participation and involvement in science teaching, resulting in students' more significant commitment and better learning, especially for subjects requiring abstract concepts such as chemistry. A study conducted with chemistry students [20] sought to increase motivation since students generally consider the contents of the chemistry curriculum to be abstract and challenging to learn, mainly due to the difficulty in relating chemistry to the world in which they live. Therefore, the authors used a hybrid game (combining a board game with an app) to study organic acids and bases, where students advanced in the game by practicing their knowledge acquired in the game classroom [21]. The research showed that the game promoted the interaction among students and improved the results obtained in tests with minimal supervision from their teacher.

Another experience was conducted in XMOOC courses in Mexico on the topic of clean energies and technologies [22]. In this educational experience, the authors included gamification and assessed the results in three dimensions: cognitive, social, and emotional. In this course, activities that promoted the self-regulation of learning were included, using elements such as immediate feedback, multiple attempts, boards, and badges [23]. The 
results showed that $90 \%$ of the participants agreed that they felt more motivated and challenged than traditional methods. The authors considered that this methodology could improve the participants' experiences of these courses in online teaching.

Finally, another study conducted in an ocean science course used game-based learning to develop scientific competencies in students based on the Program for International Student Assessment (PISA). After applying the methodology in an experimental group, they obtained better skills than those who did not perform these activities. This model positively affected participants' learning and inquiry competencies. The authors suggested further research on the positive impact of gamification activities on these skills [24]. Although these studies reported positive results, measuring the impact on motivation and interest, we also needed to analyze whether the motivation was caused by extrinsic stimuli such as rewards (where learners may see their engagement decrease when they no longer receive them) [25], or if motivation was intrinsic and kept the students interested in learning. Therefore, the following section reviews the concepts and the dimensions assessed by the instrument used in this study to measure motivation and engagement.

\subsection{Motivation and Engagement}

Several studies report student motivation and engagement as essential factors in achieving higher levels of success in the completion of their courses. Motivation is the internal process that provides a person with the energy to direct his or her efforts toward satisfying a need [26]. On the other hand, engagement refers to the manifestation of that motivation; an action contributes toward attaining a goal [27]. Both attitudes are necessary to achieve better results; however, they are challenging, especially in online educational environments.

In gamification, a commonly used framework for understanding the potential of games in motivation is Self-Determination Theory (SDT). SDT states that students have an innate tendency to engage in the classroom and that this motivation is augmented by the previously mentioned needs for autonomy, competence, and relatedness [28,29]. Autonomy refers to the freedom to choose which challenges to undertake; competence refers to the feelings of mastering the challenge in question, and relatedness refers to the experiences of recognition and acceptance that develop within these activities [13]. Games aim to integrate these principles to achieve an intrinsic motivation in students. Gamification optimizes the way for students and teachers to remain connected to each other [30]. This interconnectedness is generated by balancing extrinsic and intrinsic factors to promote real education.

One model used to identify the level of motivation in education and technology is Keller's ARCS (attention, relevance, confidence, and satisfaction) model [31,32]. This model focuses on stimulating and maintaining student motivation, so it is required that each of the categories be present in the motivational strategies used in the teaching processes [33]. The categories defined in the ARCS model [32] are:

- Attention: consists of capturing students' interest and stimulating their curiosity to learn. It implies that strategies such as variability, inquiry, and engagement are included.

- Relevance: consists of considering the students' personal needs or goals to generate a positive attitude. These strategies include the need for play, future usefulness, modeling, and choice.

- Confidence: helps students believe they will succeed, and that they know how to control this success. This attitude requires strategies which improve self-confidence, identify learning requirements, and raise expectations, among others.

- Satisfaction: refers to reinforcing achievements with internal or external rewards. These strategies consider unexpected rewards, positive outcomes, negative influences, and scheduling.

An engagement in education makes the learner more connected to the learning process. According to Haruna et al. [34], engagement can be assessed in students in different 
ways, with observable behaviors such as body language, participation, confidence, and enthusiasm, as well as unobservable behaviors such as individual attention, clarity of learning, and orientation. These characteristics cause the learner to develop a sense of engagement and ownership in their learning process. They are organized into three main categories: enjoyment, interest, and challenge [35]. A systematic literature review conducted by Loureiro et al. [36] found that, to improve engagement in participants, designers must provide realistic environments with tools which are easy to use for both teachers and students. In addition, teaching must be more practice-oriented, where the student learns by practical means. Recent studies have found that gamification contributes to a friendlier environment which positively impacts engagement, especially in the short term.

In this study, engagement is analyzed in two dimensions: emotional and cognitive. Emotional engagement refers to positive reactions to school, such as enjoyment and the experience of belonging [37]. On the other hand, cognitive engagement refers to strategic learning skills, motivation, and problem-solving [38,39]. Both types of engagement are correlated with gamification strategies to drive students' motivation and academic success.

Some studies have been developed during the current COVID-19 pandemic, analyzing how gamification can improve students' motivation and commitment. Nieto-Escamez et al. [40] conducted a study to review the results by applying gamification during the health contingency period. The authors searched different databases such as Scopus, ERIC and Semantic Scholar and identified 11 papers from chemistry, business, computer science, biology, and medicine. The results showed that gamification was innovative and attractive for all cases and was perceived as a fun activity. Nevertheless, some students did not engage in the activities due to having a poor psychological state due to isolation. In the reported study on chemistry [21], a game initially designed for the classroom was conducted online due to remote learning. The students rated it satisfactory as an educational tool; however, there were no differences between the grades of students experiencing the gamified system and those who took the traditional course.

One of the research findings by [40] is that the literature is more oriented toward gamification in STEM subjects (science, technology, engineering and mathematics). This is potentially caused by the difficulties in carrying out laboratory practices at home after face-to-face classes were suspended. Although these studies sought to improve student motivation and engagement, these efforts were improvised, and thus the gamified environment was poorly planned. Therefore, some of them had little or no student participation, failing to increase intrinsic motivation to perform the activities. The authors suggested detailing the objective of the gamified activity and providing continuous support from the teacher. Finally, they considered that gamification could become an excellent form of learning support, combined with traditional learning activities. The studies suggested that it could provide an alternative, technology-supported, post-COVID-19 learning initiative through its incorporation into academic programs.

Another study in recent literature sought to identify the different elements in online education to measure the results obtained for student motivation when using strategies such as gamification. The authors found that online activities required more engagement, self-regulation, and interest to participate in the activities, so technology played a vital role in improving learning methodologies, motivation, and engagement to increase participation in the assigned tasks [41]. To conduct this study, the authors applied a survey to students and parents, where they determined that online education required students to be more involved and had better pull factors. In addition, respondents indicated that the use of smartphones to access virtual platforms increased, which in turn increased the number of technical problems. The authors mentioned that eye contact did not exist in this format if students did not turn on the camera, making it difficult to know whether they understood the concepts which were taught. Finally, they indicated that although gamification activities were incorporated, few students were involved in these processes, so they recommended creating gamified environments which improved student-teacher interaction and collaborative learning in group activities. As in the previous studies, gami- 
fication is seen as an alternative, even after schools reopen, to continue using technologies (such as mobile applications) that allow for interactions and improve learning.

Raju et al. [42] sought to identify the results of gamification activities in engineering courses during the pandemic. The authors mentioned that in virtual environments, it was difficult for teachers to observe students' attention and to be able to take actions to improve motivation, measures which were more easily achieved in in-person classes. Therefore, they proposed using different technological tools with gamification activities to maintain students' motivation. To measure the result, they conducted surveys and observed as the course progressed, students increased their participation, attaining $100 \%$ engagement with the proposed activities. The authors concluded that student engagement became vital to achieving better participation and learning results in these virtual environments with no face-to-face interaction with the teacher.

According to the literature reviewed, although gamification activities are being carried out to improve student motivation and engagement in distance learning environments, greater student participation and better teacher preparation are still required. Studies show that integrating gamification in distance courses was accelerated and with little planning on the part of teachers so that planning activities and teacher involvement were necessary to increase the intrinsic motivation of the students [40]. In addition, it was identified that a greater student involvement and the formulation of other proposals for technology-based gamified environments were needed, which were maintained even after the pandemic [41]. Therefore, our study seeks to fill this gap by presenting a gamification proposal that is simple to use and seeks to increase student participation in online classes, with teachers monitoring their progress at all times. We believe that the benefits of these strategies can improve student learning, motivation, and participation in online courses. It can be helpful to continue using technology in gamified environments to support education in the post-COVID-19 era.

This study aimed to present the results of implementing a gamification strategy in two chemistry courses to improve student motivation and engagement. The proposed activities were mediated by gamification to increase the interest of the participants.

The importance of this study lies in the fact that the innovative proposal developed in this research is not exclusive to chemistry or science in general but is fully adaptable to other disciplines. In addition, this format can be used in different contexts (blended or face-to-face) which require improving student learning outcomes. As a contribution, this study will be helpful for teachers, instructional designers, curriculum designers, and others interested in gamification and measuring its impact on student motivation and engagement. The instruments and pedagogical strategies used may be helpful in other disciplines as well. This study is innovative due to the simplicity of the adaptation. It proposes easy-toimplement gamification strategies that teachers can use by facing challenges such as the lack of time and lack of knowledge of proposals which help improve student motivation and engagement.

\section{Materials and Methods}

This section describes the methodology followed in this study, first explaining the general details of both subjects, how the students interacted with the technology, the organization of Q1028 and Q1029, and the definition of gamification. Then, the sample description, instruments, and how the data analysis was performed. The contextual focus of this study was a completely online environment caused by the pandemic. The research sought to measure the effects of the proposed gamification activities on student motivation and engagement in this context. It was expected that it could also be used in blended or face-to-face environments with technology support.

In this research, a quasi-experimental study was conducted to collect data to evaluate a studied phenomenon and identify the intervention's effects [43]. The study was conducted at a university in central Mexico through two undergraduate chemistry courses: Fundamentals of the Structure and Transformation of Matter (Q1028) and Analysis of the Structure and 
Transformation of Matter (Q1029) in the 2020-2021 academic year. These were consecutive subjects in the first-year curriculum of the engineering majors studying under the new Tec21 educational model at Tecnologico de Monterrey [44]. The courses were implemented in an online format known as the Digital Flexible Model. The 100-point grading scale had a passing score of 70 . The study had 48 students from various engineering majors (22 students studying Q1028 and 26 studying Q1029) comprising the sample to know the students' assessment of the gamification strategy.

\subsection{General Details of Courses Q1028 and Q1029}

Among the thematic contents in these courses are the properties and transformations of matter, how they occur, and the speed of changes; they describe the atomic structure and reactivity of substances. These theory subjects each consist of ten two-hour sessions. For this study, an assistant professor was essential for counting points and the continuous communication with the students. Both subjects consisted of several sections with different weightings, as Figure 1 explains below.

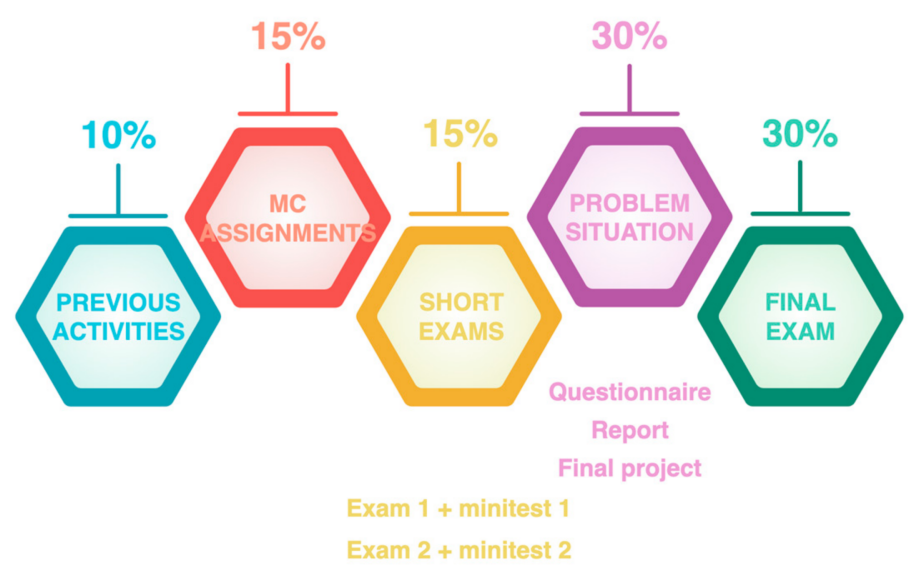

Figure 1. Diagram with the different sections and their respective weightings of courses Q1028 and Q1029.

\subsection{Use of Technology}

In this study, several gamification activities were carried out, some in class and others with computer support, including tasks and evaluations in the Canvas learning management system, multiple-choice quizzes, and, finally, previous activities and assignments in the Mastering Chemistry (MC) platform from Pearson. All calculations to score the achievements were completed in an Excel spreadsheet and then published in Canvas so that each student could track their grades and bonuses privately.

\subsection{Organization of $Q 1028$ and $Q 1029$}

2.3.1. Previous Activities and Assignments

The previous activities (PA) and assignments (A) were planned using the Mastering Chemistry platform, as explained below:

- Three previous activities were planned, which consisted of a pre-class reading of the book Chemistry: A Molecular Approach by Tro et al. [45]. Students had to solve ten straightforward exercises to demonstrate a basic knowledge at the beginning of the class.

- Five assignments were scheduled (usually 1 per week), with 15 exercises on average, more complex than the previous activities, including all the content seen in the week. Each exercise could be repeated three times.

Some exercises, usually solving numerical problems, were automatically modified when performed again to learn how to perform them effectively. Once the previous activity 
or assignment was finished, students could repeat it three times for more practice and improve the grade they obtained.

\subsubsection{Problem Situation}

The problem situation (challenge) is the central axis of the subjects in the Tec21 model [44], where the challenge-based learning (CBL) strategy [46] is applied. Through CBL, the student is actively involved in an actual situation connected with the real-world environment. CBL involves analyzing, proposing, and implementing a solution based on the knowledge obtained during classes. Students were randomly divided into teams of four to six people to work on the challenge.

The topic covered in Q1028 was an oil spill in a northern Mexican city. The learning objective was to link concepts of solubility of polar and non-polar compounds through chemical bonding. Q1029 dealt with the functioning of automobile airbags from a chemical perspective, studying the chemical reactions in an airbag and their stoichiometry and thermodynamics.

Both Q1028 and Q1029 required two scheduled advances (quizzes) and a final paper. The first advance consisted of a questionnaire with ten multiple-choice questions that each student had to solve outside of class. They could answer twice. The advances' intentions were to involve them in the situation they had to solve. Subsequently, the students had a week to deliver a group report that elaborated on a series of tables directed to the end of the course. They then made a creative video as evidence of their final work. The video integrated all the content and proposed a solution to the problem studied and reflected on the possible environmental and social impact.

\subsubsection{Short Exams and Final Exams}

Two short exams with fifteen multiple choice questions were given in sessions 5 and 8 , respectively, in both courses. At the end of the course, a final exam in session 10 provided a summative evaluation, which contained between 8 and 10 multiple options and three problems with several questions to be answered. Great care was taken to elaborate the exams, preferably from the third level of Bloom's taxonomy, although there were some at the comprehension level.

Each question had 2 or 3 different versions (always taking care that the same content was evaluated); thus, all the students' exams were different, although as similar as possible in difficulty. Each exam had a maximum grade of 100 points. The exams were taken during class time with the help of the LockDown Browser program to block other computer applications. In addition, before the start of each assessment, students had to show their workstations one by one. They were allowed only a sheet of paper, pencil and eraser, a calculator, and a form provided by the teacher. After each short, out-of-class exam, students could solve a short mini-test with six additional multiple-choice questions (each question worth 3 points) only once. This mini-test was intended to improve the grade obtained in the corresponding short exam, with a maximum possible grade of 100 points. The schedule of the subjects is shown in Figure 2.

\subsection{Gamification System}

Our project intended to provide an entertaining and enjoyable experience. At the same time, students learned chemistry, and we determined whether gamification could improve students' motivation and engagement with conventional activities conducted in the classroom. The basic design had to adhere to the three principles of gamification: relatedness, competence, and autonomy [18,19]. Relatedness became very relevant because classroom interactions in small group teaching were a conducive environment for interactions among students and even more necessary in an online format. Table 1 below summarizes all the possible achievements that could be obtained, the conditions necessary to obtain them, and the respective rewards. 


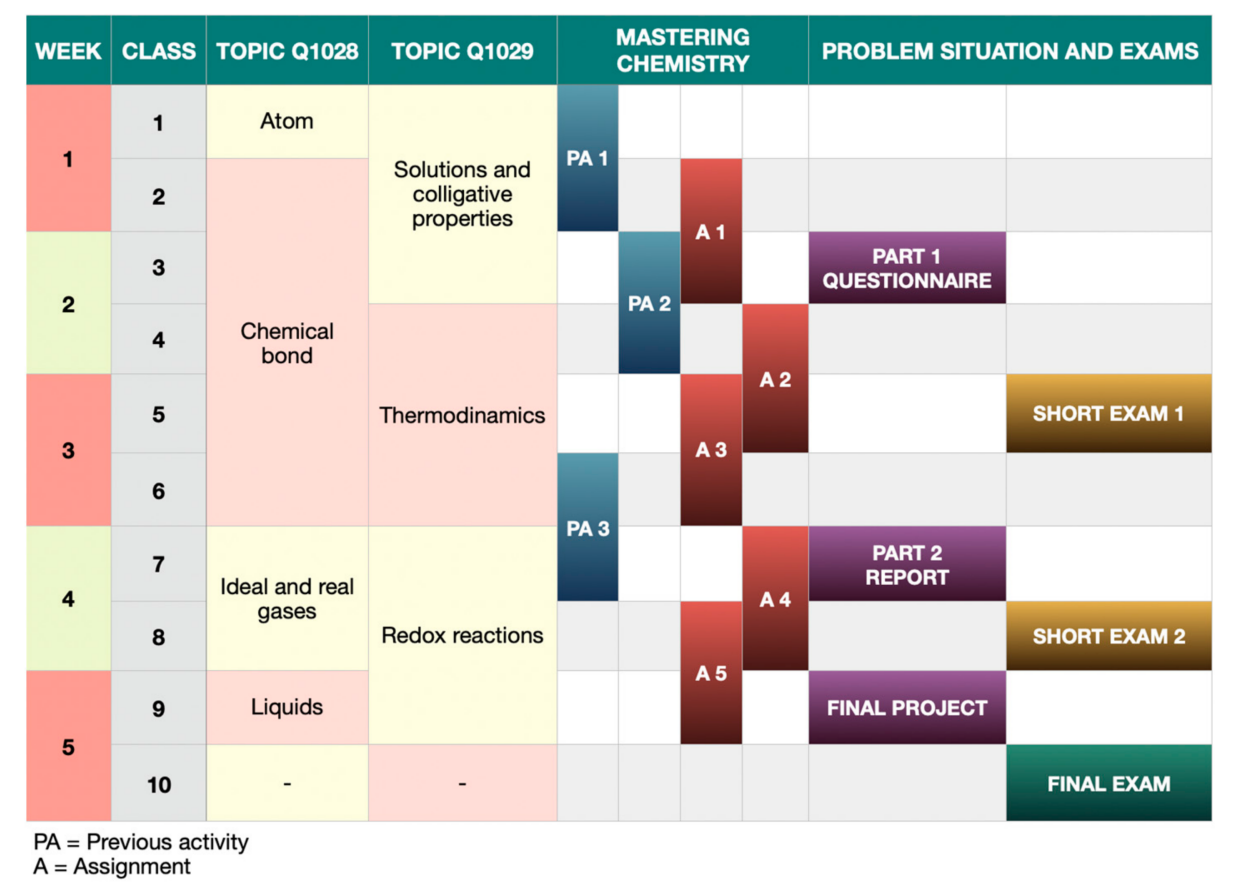

Figure 2. Calendar of subjects Q1028 and Q1029 with due dates for all assigned activities.

Gamification activities can be divided into long-term, medium-term, and short-term activities.

\subsubsection{Long-Term Activities}

Since class attendance is optional at Tecnologico de Monterrey, students could obtain 0.5 points that would be added to the final average if they achieved perfect attendance (only one excused absence with prior notice was allowed) (Figure 3a). Additionally, due to the difficulty that teachers had with students not turning on the cameras during classes [47], they were incentivized with 0.5 points toward the overall grade if they kept the camera on at all times, having to notify the teacher if they were absent for a moment (Figure 3b). Finally, they were offered one extra point for participating in this research study if they completed a questionnaire at the beginning and end of the course to measure academic performance (pre-test and post-test) and completed the perception survey on the gamification technique (Figure 3c).

\subsubsection{Medium-Term Activities}

To help students retain knowledge in each of the three required readings corresponding to the previous activities, we urged students to create mind maps (MM) (Figure 4). A mind map is a didactic strategy that facilitates organizing ideas and thoughts and hierarchizes information intuitively [48]. For their correct evaluation, students had a checklist. For each MM correctly performed, they could obtain 0.5 extra points in the final integrative exam.

As mentioned earlier, science subjects and chemistry generally had a certain degree of difficulty for students [49]. In addition, due to the tight time to develop the curriculum, platforms such as Mastering Chemistry (MC) helped students practice at home with more exercises. To motivate them to practice more and improve learning, we offered students an achievement which, depending on the average they obtained in the homework grades, could benefit extra points in the final integrative exam (Figure 5). The first possible achievement was to complete all the MC assignments with an average between 70 and 89.9 points, thus being awarded one extra point in the final exam. The next step would be to achieve an average between 90 and 96.9, or to obtain 2 points. Finally, achieving an average of 97 
or higher, the student was awarded 3 points on the final exam. It should be noted that obtaining one of these achievements automatically excluded the others.

Table 1. Conditions to obtain all possible achievements, together with their respective awards.

\begin{tabular}{|c|c|c|}
\hline Achievement & Condition & Reward \\
\hline Praise the Sun! ${ }^{1}$ & Have perfect attendance. & 0.5 extra points in the final grade. \\
\hline Knock, knock ... are you still there? ${ }^{1}$ & $\begin{array}{l}\text { Leave your camera on during the entire } \\
\text { session (stay in frame). }\end{array}$ & 0.5 extra points in the final grade. \\
\hline Legendary Research $^{1}$ & $\begin{array}{l}\text { Complete the survey and answer the } \\
\text { pre-test and post-test. }\end{array}$ & 1 extra point in the final grade. \\
\hline Season passes ${ }^{2}$ & $\begin{array}{c}\text { Create mind maps }(\mathrm{MM}) \text { of selected } \\
\text { readings. }\end{array}$ & $\begin{array}{l}0.5 \text { extra points in the final exam's grade } \\
\text { for each MM. }\end{array}$ \\
\hline Are You Not Entertained? ${ }^{2}$ & $\begin{array}{l}\text { Complete all MC Assignments (average } \\
\text { score from } 70 \text { to } 89.9 \text { ). }\end{array}$ & 1 extra point in the final exam's grade. \\
\hline Now That's an Achievement! ${ }^{2}$ & $\begin{array}{c}\text { Complete all MC Assignments with an } \\
\text { average score equal to or greater than } 90 \text { up } \\
\text { to } 96.9 .\end{array}$ & 2 extra points in the final exam's grade. \\
\hline Head Case $^{2}$ & $\begin{array}{l}\text { Complete all MC Assignments with an } \\
\text { average score equal to or higher than } 97 .\end{array}$ & 3 extra points in the final exam's grade. \\
\hline Upright Citizens $^{2}$ & $\begin{array}{l}\text { Supportive, willing to help, showing } \\
\text { interest in others, respectful, positive } \\
\text { attitude in the problem situation. }\end{array}$ & $\begin{array}{l}2 \text { extra points in the problem situation's } \\
\text { grade ( } 1 \text { person per team). }\end{array}$ \\
\hline A Bit of This, A Bit of That ${ }^{3}$ & $\begin{array}{c}\text { Solving exercises on the } \\
\text { whiteboard/Answering classmates' } \\
\text { questions in class/Solving quiz } \\
\text { problems/Answer the teacher's questions } \\
\text { correctly. }\end{array}$ & $\begin{array}{l}1 \text { token for each participation. Every } \\
3 \text { tokens earn } 1 \text { ticket. Cumulative. }\end{array}$ \\
\hline
\end{tabular}

${ }^{1}$ Long-term achievements. ${ }^{2}$ Medium-term achievements. ${ }^{3}$ Short-term achievements.
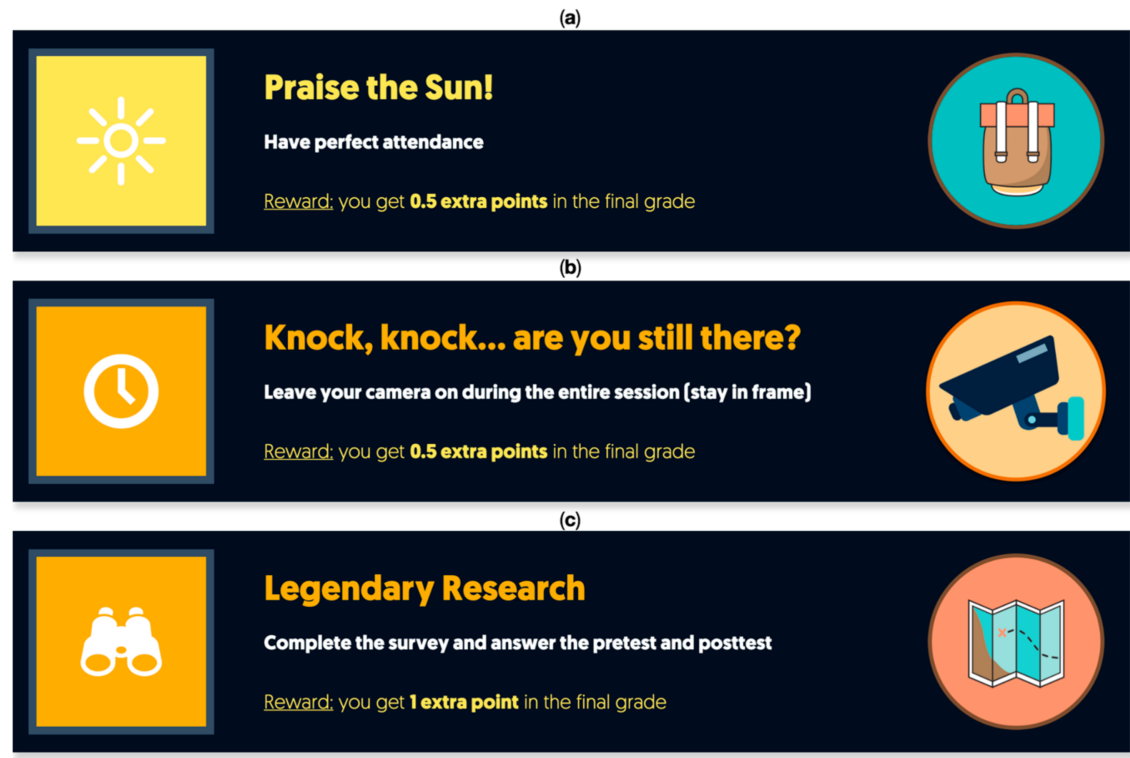

Figure 3. Long-term achievement based on (a) attending class, (b); keeping the camera on, and (c) collaborating with the research study conducted. 


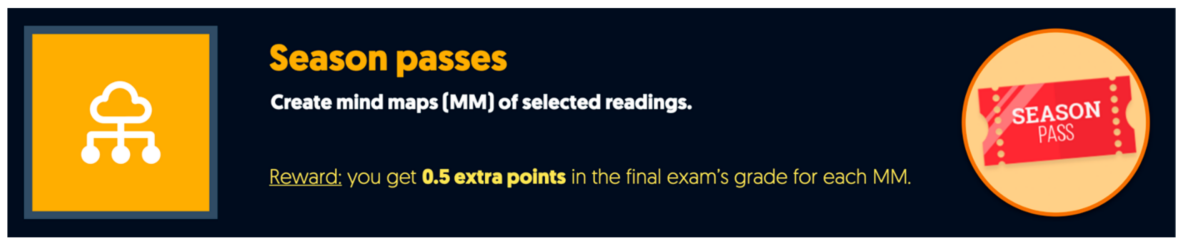

Figure 4. Mid-term achievement creating mind maps to earn points on the final exam.

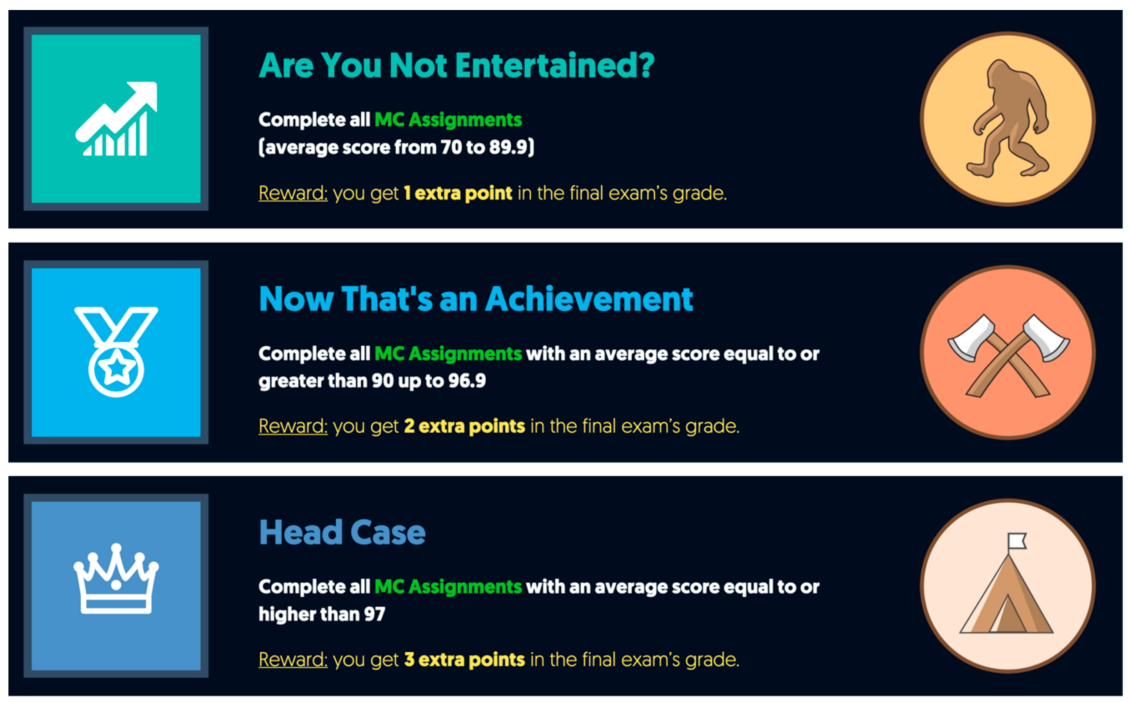

Figure 5. Medium-term achievement based on the grades of the MC assignments.

Students in group settings collaboratively achieved much greater conceptual understanding than students in courses in an individual setting [50]. Likewise, individual responsibility was an essential aspect of positive interdependence theory. Because students recognized differences in contributions when working collaboratively [51], an achievement was designed that rewarded the students within each team who maintained a positive attitude, were respectful to others throughout the project, showed interest in others, and were always willing to help his or her group (Figure 6). Each student had to vote for one of his or her teammates (self-voting was not valid). The achievement was effective when the student received at least two votes. If there were two or more winners with the same number of votes, they all won the achievement.

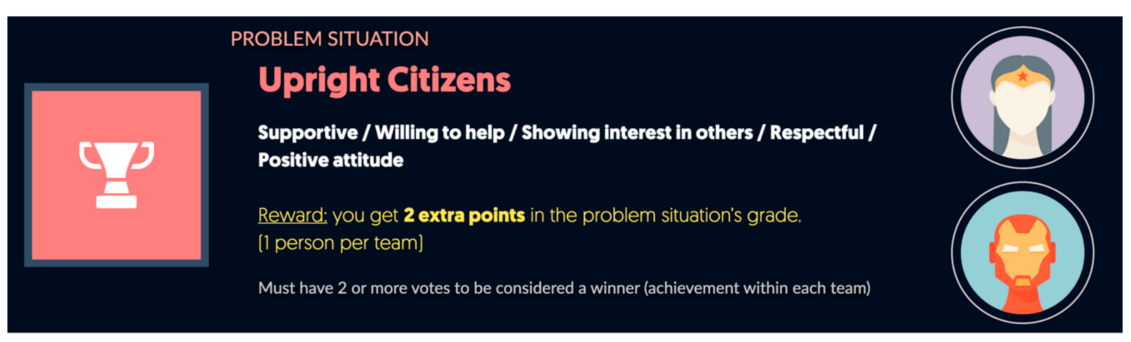

Figure 6. Medium-term achievement for the problem situation section.

\subsubsection{Short-Term Activities}

Students could obtain tokens, which were converted into tickets once three tokens were collected. These were cumulative and could be used whenever they wanted until the end of the course. At the end of each class, with the help of the assistant teacher, the students were notified of how many tickets they had accumulated. These tickets could be used in two ways (Figure 7): 
- Lifeline: they could request to open a previous activity or assignment extemporaneously for $24 \mathrm{~h}$ without any penalty.

- Narrow it down: in the short exam or final exam, they could ask if one of the multiplechoice items was correct or not, where they would get a short answer privately from the teacher or teaching assistant: YES or NO. Each multiple-choice question had five possible items (A through E). The student was allowed to use several tickets on the same question, so if they asked that the correct item was option B and it was incorrect, they could use another ticket for the same question.

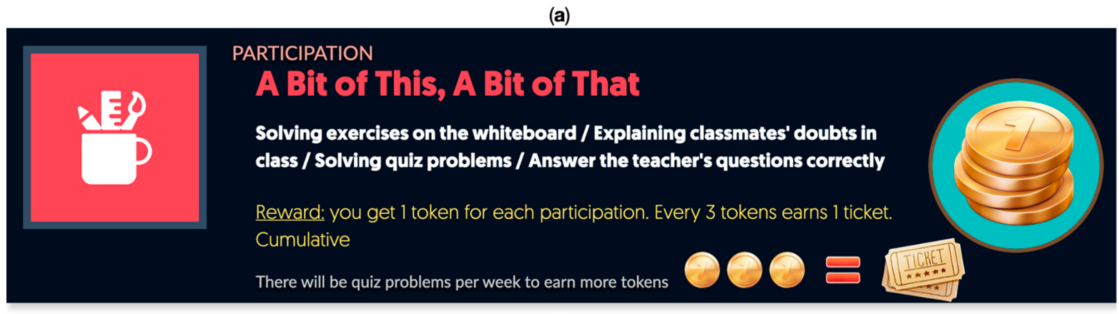

(b)

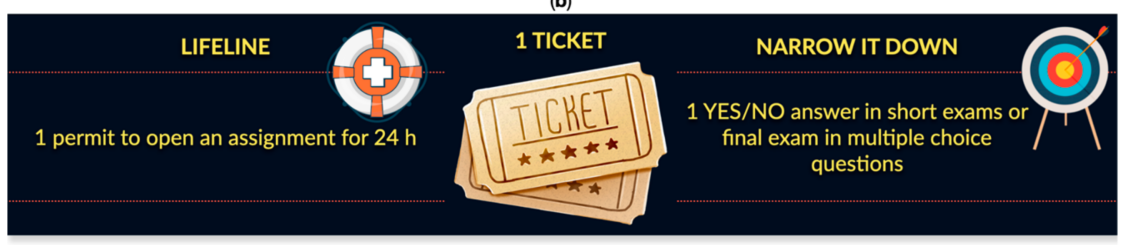

Figure 7. (a) Short-term achievement: How to obtain tickets through participation. (b) Two different ways to use tickets.

The Lifeline achievement was conceived because the subjects in this educational model usually contained a lot of content, and thus some work was likely to be forgotten. Thus, requests to reopen an assignment changed from being a favor asked to the teacher to a right that students had if they participated in class.

Additionally, Narrow it down was included for those who completed all the assignments and could benefit from using these tickets during any exam.

Students had several ways in which they could earn the tokens. During class, students who wanted to solve the proposed exercises were rewarded with a token. There were times when all students who wanted to solve the exercises were asked. At other times, some students were selected, usually the shyest, those who were afraid of making mistakes, or those who had fewer tokens, so that there would be a better balance of points among all students, and not just the same people who always participated. In addition, depending on the number of exercises, one or two supervising students were chosen to check that they were correctly solved. They helped their assigned classmates if they could not complete the proposed exercise. Additionally, a weekly test was assigned, either in class or after class, which included three to five multiple-choice questions through a multiple-choice question application (Wordwall). Students could solve it only once and each correct answer was equivalent to a token.

The design aimed for students to obtain points and permissions (see Figure 8), which had long-term benefits (extra points for the final grade), medium-term benefits (activities that benefit the final exam or problem situation), and short-term benefits (tokens could be obtained for each participation and were later converted into tickets). For this reason, a solid and transparent approach was required to avoid any problems affecting the points awarded. 


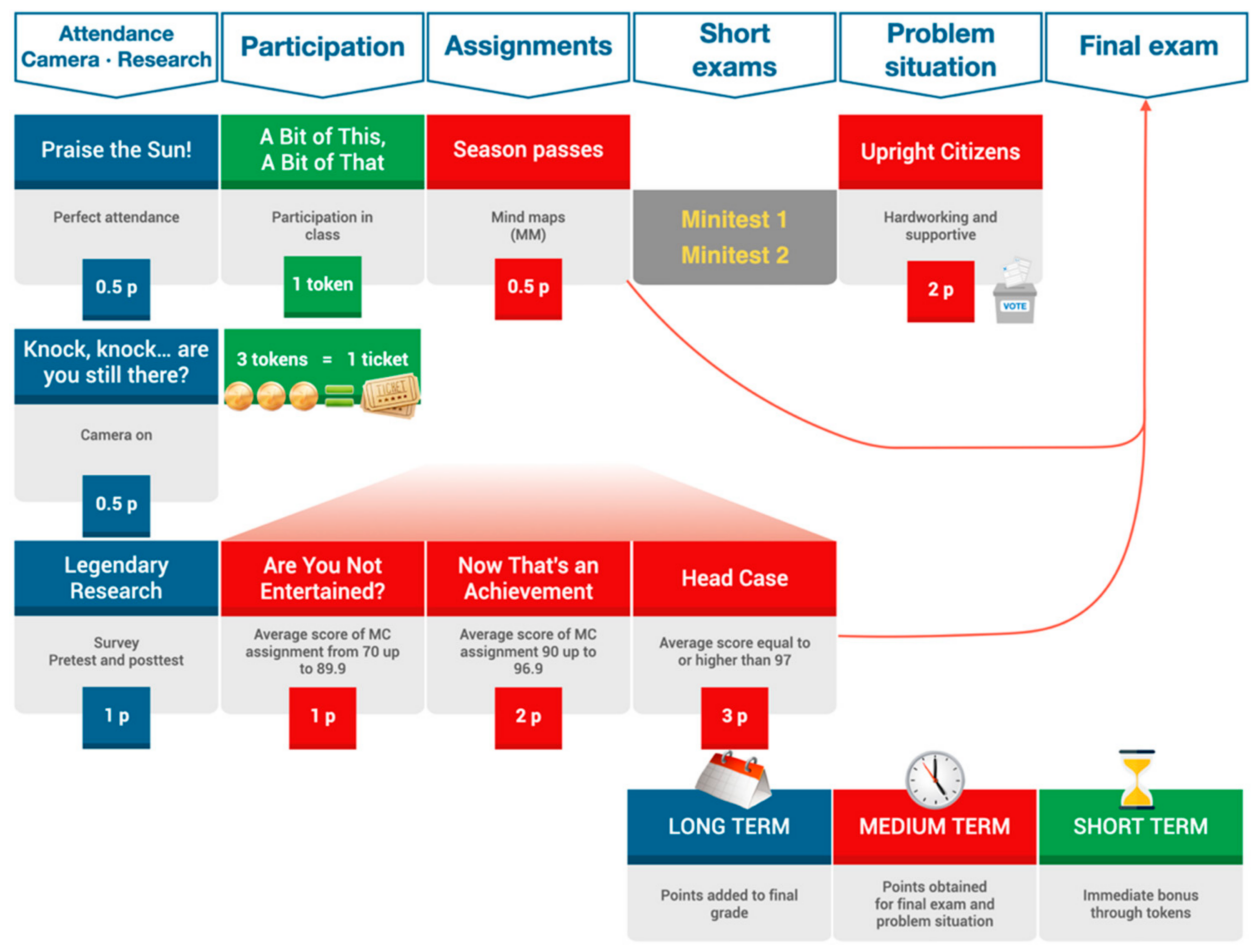

Figure 8. Diagram with achievements in the short, medium, and long term.

\subsection{Sample}

The sample was selected intentionally and was composed of 48 students from Tecnologico de Monterrey. Of these students, 34 were male, and 14 were female, divided into two groups in total. The students belonged to different engineering majors and had to take both courses as a requirement during the first semester of their studies.

\subsection{Instruments}

We administered two instruments: an assessment survey and a knowledge test before and after the gamification activity (pre-test and a post-test) to conduct this study. Participants received credit for completing the three activities as an extra assignment; however, the data were kept anonymous so that responses to the survey items could not be linked to individual course participants.

\subsection{Perception Survey}

To contribute to studies which sought to improve student motivation and engagement through gamification, we applied a survey to identify the impact of these factors on chemistry students. The objective was to discover the students' impressions of gamification as a didactic tool in science subjects such as chemistry. The survey was applied at the end of the course. It consisted of 24 multiple-choice items and one open-ended question that was added to Q1028 students to know how they perceived the application of this strategy in their own words: "Using a short sentence, what was your experience regarding the use of gamification in class?"

The study was based on a validated questionnaire adapted from [34] and translated into Spanish. The 16 items of the ARCS model (with some modifications) on motivation assess learning effectiveness per four components of motivation: attention, relevance, confidence, and satisfaction. Four questions in each group [32] were taken into account. In addition, eight questions corresponding to engagement, both emotional and cognitive, were adapted, again with four questions each. All items used a 5-point Likert scale describing 1 (Strongly disagree), 2 (Disagree), 3 (Neutral), 4 (Agree), and 5 (Strongly Agree). The items of the instrument are presented in Table 2. 
Table 2. Students' assessment of gamified chemistry courses.

MOTIVATION
Attention
MA1. Something was interesting at the beginning of this subject that caught my attention.
MA2. The teaching approach used (gamification) was eye-catching.
MA3. The activities designed using this teaching method seemed more attractive to me.
MA4. The teaching method used makes chemistry more interesting.

\section{Relevance}

MR1. I could relate the content taught through this method to things I have thought about in my future life.

MR2. The content taught me that this approach would be useful during my time at university.

MR3. The instructional style gives the impression that the course is worth learning. MR4. The content of the teaching approach will be useful to me.

\section{Confidence}

MC1. I was able to understand quite easily the material taught through this teaching method.

MC2. The exercises were too easy when using this teaching method.

MC3. The excellent organization of the content helped me to be confident that I would learn better with this approach.

MC4. The teaching approach was simpler to understand than I would have thought.

\section{Satisfaction}

MS1. I very much enjoyed learning with this teaching method.

MS2. It was a pleasure to learn chemistry through this pedagogy.

MS3. Taking the subject through this teaching method gave me a satisfying sense of accomplishment.

MS4. I learned surprising or unexpected things with this teaching method.

\section{ENGAGEMENT}

Emotional engagement

EE1. The gamification strategy made it easy to understand the learning content.

EE2. I learned effectively in this course as the method of instruction was engaging.

EE3. The teaching method used facilitated my active participation in the subject matter.

EE4. The instructional approach used during the course interested me.

Cognitive engagement

CE1. I demonstrated my interest and enthusiasm and had a positive attitude during the course.

CE2. This teaching method was relevant to engage students in chemistry courses.

CE3. The teaching strategy enhanced my participation in the course.

CE4. I focused on learning activities that had bonuses.

Q1. Using a short sentence, what was your experience of using gamification in the classroom?

\subsection{Pre-Test and Post-Test}

For each subject, a different pre-test and post-test with 12 multiple-choice questions, based on the corresponding syllabus, was conducted to evaluate the learning obtained by the students. The pre-test was applied between classes 1 and 2, while the post-test was administered between classes 9 and 10. The exams were placed in Canvas, and the students had $40 \mathrm{~min}$ to solve them outside class. At the end of the pre-test, the system only showed the student the grade they attained, while in the post-test, it also showed the correct answers and the respective feedback. In this way, the student used this post-test as practice before the final exam.

The Q1028 questionnaire inquired about the nature of matter and its properties (atom, chemical bonding, periodicity in the periodic table, geometry and polarity in molecules, intermolecular interactions, solubility), the behavior of gases (ideal and real) and phase diagrams. In Q1029, questions were developed on solutions and their colligative properties, chemical energy (thermodynamic laws, enthalpy and entropy of reaction, and free energy), chemical energy, and electrical energy (oxidation-reduction reactions and electrochemical cells).

\subsection{Data Analysis}

The quantitative data collected were analyzed using IBM SPSS Statistics version 26. First, to corroborate the reliability of the items included in this survey study, Cronbach's 
alpha reliability test was applied, whose result $(\alpha=0.95)$ confirmed that these questions were sufficiently reliable to be used as a research instrument, surpassing the values of previous research [34]. Subsequently, descriptive statistics were calculated for the students' responses, and percentages were compared to determine if differences existed and which responses had the highest and lowest values for analysis. The responses to the pre-test and post-test were compared to analyze the score differences after the gamification activity to determine if the students improved their test performances.

\section{Results}

Of the 48 participants, $71 \%$ were male (34), and $29 \%$ were female (14). Seventy-five percent were between 18 and 19 years old, and the other $25 \%$ were between 20 and 21 . Regarding the students' majors, most were Sustainable Development Engineering (SDE) and Industrial and Systems Engineering (ISE), with 12 participants for each major, followed by Mechatronics Engineering (8 participants). The distribution of students by major is shown in Table 3.

Table 3. Distribution of students by major.

\begin{tabular}{ccc}
\hline Major & N & Percentage \\
\hline Sustainable Development Engineer (SDE) & 12 & 25 \\
\hline Industrial and Systems Engineer (ISE) & 12 & 25 \\
\hline Mechatronics Engineer (ME) & 8 & 16.7 \\
\hline Biotechnology Engineer (BTE) & 3 & 6.3 \\
\hline Civil Engineer (CE) & 3 & 6.3 \\
\hline Innovation and Development Engineer (IDE) & 3 & 6.3 \\
\hline Chemical Engineer (CE) & 2 & 4.2 \\
\hline Mechanical Engineer (ME) & 2 & 4.2 \\
\hline Data Science Engineer (DSE) & 2 & 4.2 \\
\hline Biomedical Engineer (BME) & 1 & 2.1 \\
\hline Total & 48 & 100 \\
\hline
\end{tabular}

To compare the results and determine if there were differences among the students due to the relevance of chemistry within their majors, we divided them into two groups. One group had majors where the primary focus was chemistry (henceforth called "chemical majors") and the others had majors where chemistry was not the main focus ("non-chemical majors"). The chemistry majors were BTE, SDE and CE, where 17 students participated, while 31 participated in the remaining ones.

\subsection{Achievements}

Regarding long-term achievements, beyond the optional nature of the classes, students usually chose to attend them, with $94 \%$ attendance among both groups, because they felt much content was covered in each session. They had the possibility of justifying only one absence and usually used it in situations of significant cause, such as going to the doctor. The achievement of the camera was even more successful, as $98 \%$ of the students decided to leave the camera on.

As for the mid-term activities, in Q1028, the mind maps were not very effective, as only 2 of the 24 students performed the mind maps, representing only $9 \%$ participation. In Q1029, 16 of the 26 students performed some or all the optional mind maps for bonuses on the final exam, achieving $49 \%$ participation. Two reasons could explain this: the first was that Q1028 was one of the four subjects that students must take as soon as they start college, significantly changing students from different high schools. The second reason may be that 
the Q1029 group was quite peculiar since a large percentage were very participative with excellent grades; thus, they may have been more intrinsically motivated.

The homework bonuses attained a greater acceptance. In both groups, about $56 \%$ of the students had an average greater than or equal to 97, which awarded a bonus of three points for the final exam. Of the total number of students, $19 \%$ obtained two bonus points, $15 \%$ earned 1 point, and only $10 \%$ received no bonus for this achievement.

The Upright Citizen achievement corresponds to the problem situation. Although it does not have the same function as peer evaluation, it is an incentive for students to see their efforts reflected in their collaborative work.

In terms of participation (short-term achievements), the students who participated the most had a total of eight tickets. We took extreme caution in scoring the exam questions so that using a ticket in an exam did not substantially impact the final exam grade.

\subsection{Final Grades Results}

Figures 9 and 10 show the grades obtained without any achievement in blue (nominal points), and the additional points that could be obtained through all the possible achievements are shown in orange. The average number of extra points obtained through the achievements in Q1028 was 2.83, where the range of values represented between $1.4 \%$ and $4.1 \%$ of their final grade. In Q1029, the average number of points earned was 2.38 , and the range of values was between $0.4 \%$ and $4.5 \%$ of the student's overall grade.

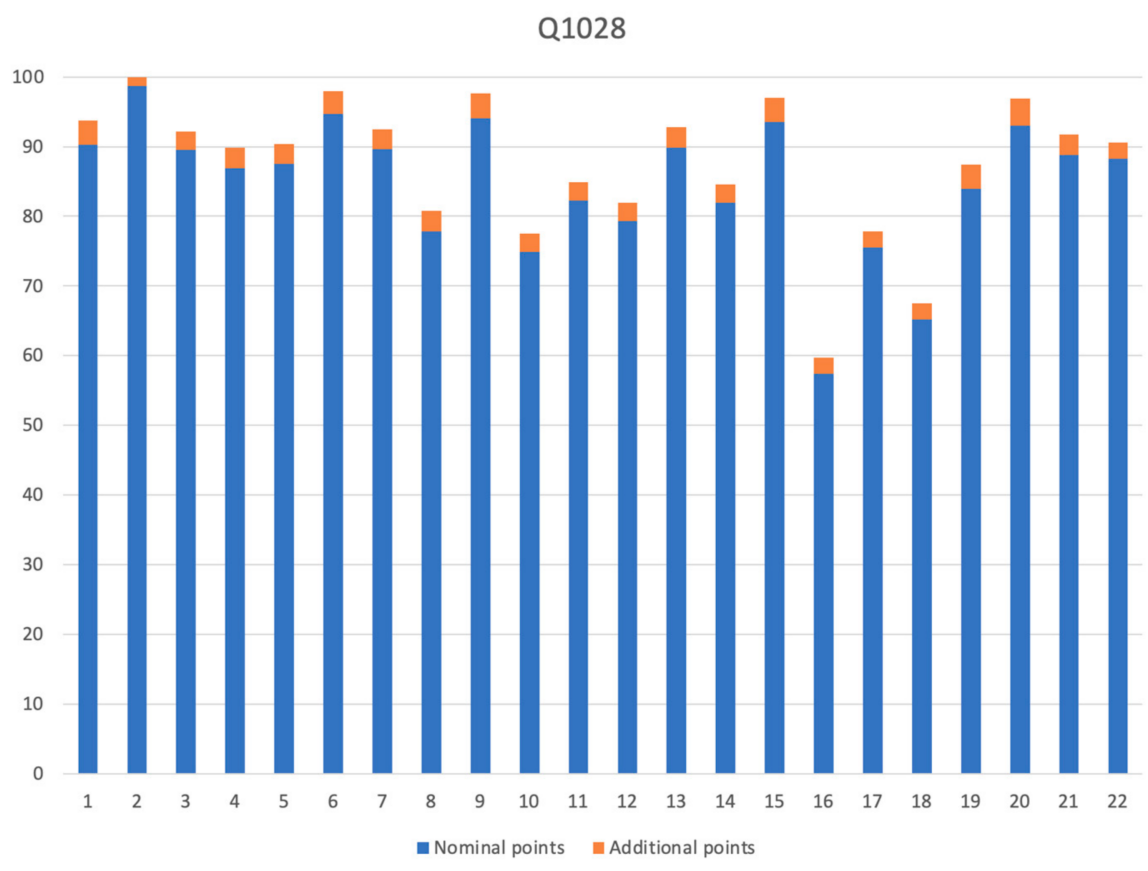

Figure 9. Final Q1028 grades excluding achievements (nominal points, blue) along with additional points earned through achievements (additional points, orange).

It should be clarified that, of the total extra points obtained, two represented the achievement of attendance, keeping the camera on, and performing the diagnostic tests along with the survey. Therefore, the points affecting the final test and the problem situation did not represent more than 2 points of the maximum possible grade.

\subsection{Pre-Test and Post-Test Results}

The interval scores for the pre-test and post-test application in Q1028 and Q1029 are presented below (Figure 11). The overall results (Q1028 + Q1029) show that the average score for both groups in the pre-test was $57 \%$. In the post-test, it was $79 \%$, with an initial pass rate of $24 \%$ (grades higher than 70 ) and a final pass rate of $76 \%$. 
Q1029

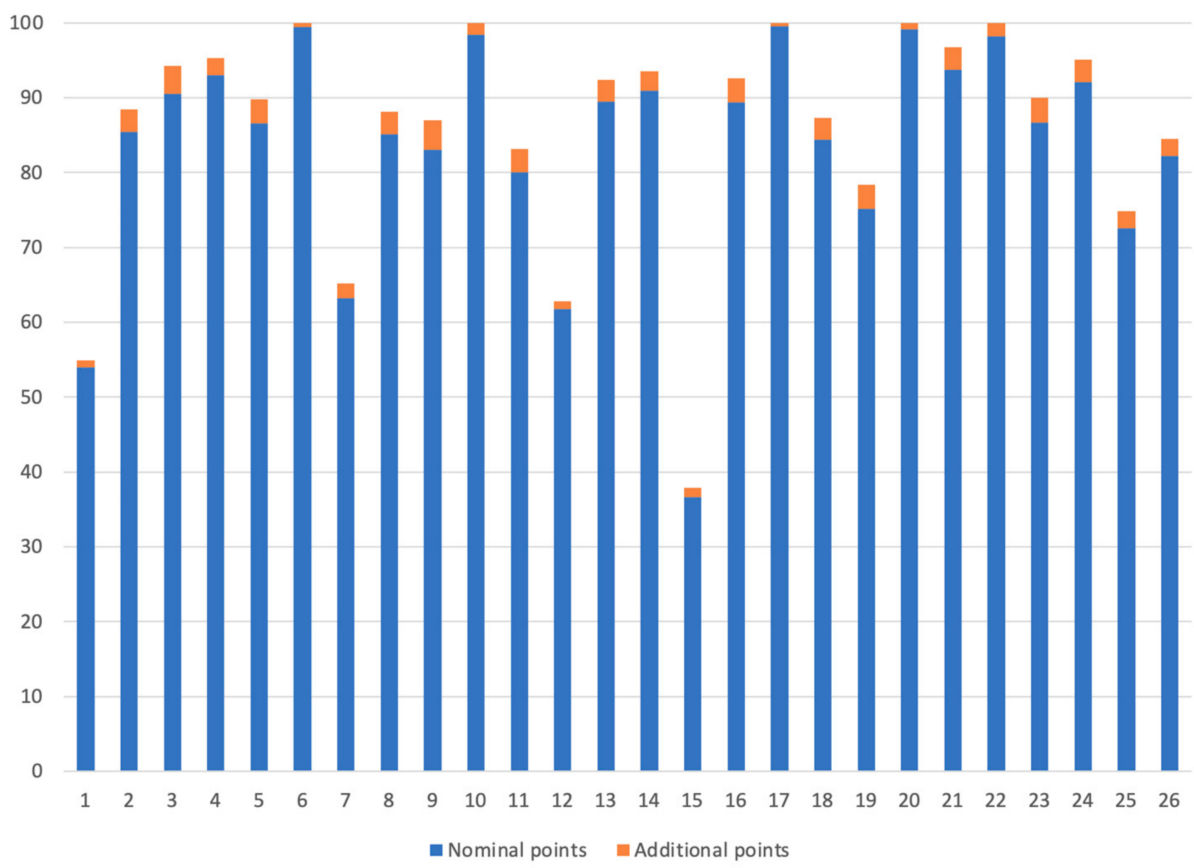

Figure 10. Final Q1029 grades excluding achievements (nominal points, blue) along with additional points earned through achievements (additional points, orange).

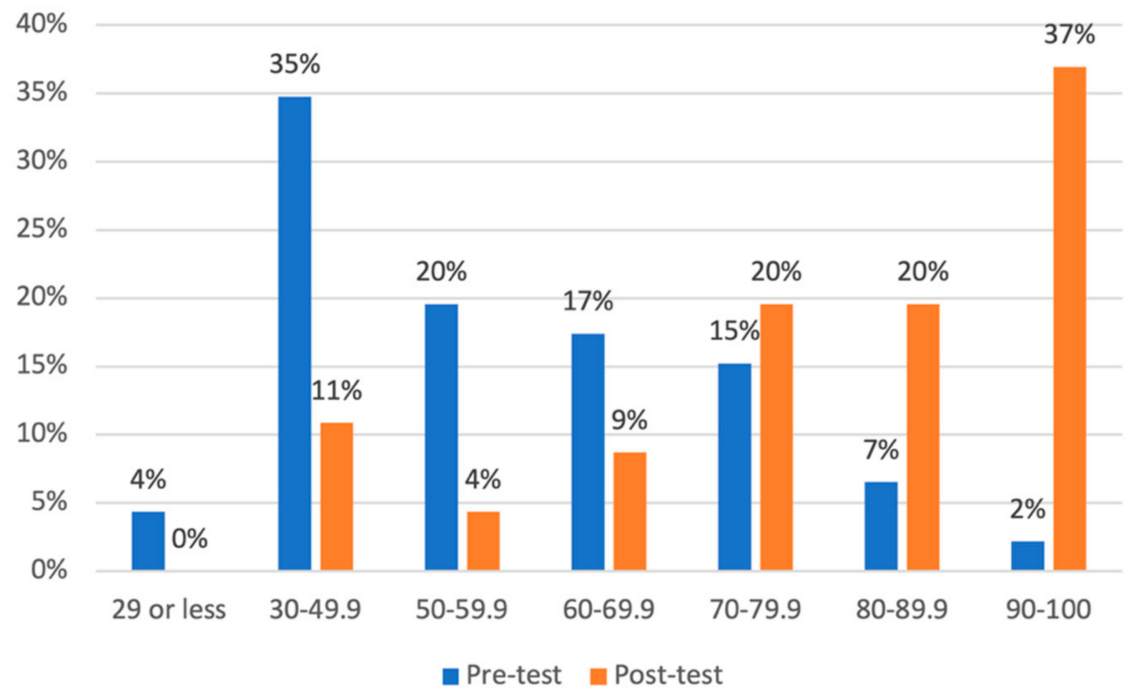

Figure 11. Difference between the overall pre-test and post-test results (Q1028 + Q1029).

\subsection{Assessment Survey Results: Analysis of the Open-Ended Question (Q1028)}

Regarding the results of the open-ended question Q1 to Q1028 ("What was your experience with gamification in class?"), most students' responses mentioned that the gamification activities allowed them to stay focused and motivated and helped them participate more in class (seven responses). Other students indicated that the activities helped them understand chemistry and content better (four responses). They also commented that the activity was enriching, equitable, useful, and interesting (three responses). On the other hand, two students responded that the process was slow and that they received a lot of information. Figure 12 shows the word cloud with the most frequent responses. 


\section{Useful and interesting \\ Helps to learn chemistry Focused and "motivated Encouraged to participate more Enriching}

Figure 12. Word cloud of Q1028 students' experience with gamification.

\subsection{Assessment Survey Results: Analysis of Questions (Q1028 + Q1029)}

According to the overall data obtained (Q1028 + Q1029), analyzing the Motivation construct, the MA2 item, "The teaching approach used (gamification) is eye-catching," had the highest value of all, with $96 \%$ positive responses (Strongly Agree + Agree, SA/A) and a mean of 4.58. For Engagement, CE2 "This teaching method is relevant to engage students in chemistry courses" led the way with $94 \%$ positive ratings (mean 4.54 ), followed closely by CE3, "The teaching strategy used enhanced my participation in the course", with 92\% (4.54).

The Motivation items with the lowest approval percentage were those of the confidence construct, MC2, "The exercises were too easy when this teaching method was used," with $42 \%$ positive ratings and a mean of 3.23. Three items from the relevance construct, MR1, "I could relate the content taught through this method to things I have thought about in my own future life", MR2, "The content taught through this approach will be useful during my time at university," and MR4, "The content of the teaching approach will be useful to me" attained 56\%, $69 \%$, and $65 \%$ positive values and means of $3.54,3.69$, and 3.69, respectively. On the other hand, the item with the lowest value corresponding to Engagement was CE4, "I focused on learning activities that had bonuses" with a 75\% approval (SA/A) and a mean of 4.04, followed closely by EE2, "I have been effective in this course as the method of instruction was engaging," with $77 \%$ positive responses and a mean of 4.27 . The results are shown in Table 4 .

Table 4. Responses with students' most and least positive values in the motivation and engagement constructs.

\begin{tabular}{ccccccc}
\hline \multirow{7}{*}{ Construct } & \multicolumn{6}{l}{ STATISTICS PER QUESTION Q1028 + Q1029 (ITEM) } \\
\hline \multirow{3}{*}{ Motivation } & Item & $\mathbf{N}$ & Component & Mean & Std. Dev. & SA/A \\
\cline { 2 - 7 } & MA2 & 2 & Attention & 4.58 & 0.577 & $96 \%$ \\
\cline { 2 - 7 } & MR2 & 6 & Relevance & 3.69 & 0.803 & $69 \%$ \\
\cline { 2 - 7 } & MR4 & 8 & Relevance & 3.69 & 0.879 & $65 \%$ \\
\cline { 2 - 7 } & MR1 & 5 & Relevance & 3.54 & 0.922 & $56 \%$ \\
\hline \multirow{3}{*}{ Engagement } & MC2 & 10 & Confidence & 3.23 & 1.036 & $42 \%$ \\
\cline { 2 - 7 } & CE3 & 22 & Cognitive & 4.54 & 0.617 & $94 \%$ \\
\cline { 2 - 7 } & EE2 & 18 & Emotional & 4.27 & 0.962 & $77 \%$ \\
\cline { 2 - 6 } & CE4 & 24 & Cognitive & 4.04 & 1.148 & $75 \%$ \\
\hline
\end{tabular}

3.6. Analysis of the Questions for Chemical and Non-Chemical Majors (Q1028 + Q1029)

When comparing chemical vs. non-chemical majors, the MA2 item remains the highest, as do the overall values. In the Engagement construct, items CE2 and CE3 remain significant, with slight differences between both groups; observed in the CE2 values of $94 \%$ and $100 \%$ for chemistry majors, compared to values for CE3 of $94 \%$ and $87 \%$ for non-chemistry majors, respectively. 
The largest difference is observed in MR1, "I could relate the content taught through this method to things I have thought about in my future life," with $76 \%$ positive responses for chemistry majors, compared to only $45 \%$ for non-chemistry majors.

A significant difference is also observed in items MS2, "It was a pleasure to learn chemistry through this pedagogy," and MS4, "I learned surprising or unexpected things with this teaching method." The chemistry majors had $94 \%$ positive responses in both items, in contrast to non-chemistry majors, with only $74 \%$ and $68 \%$, respectively. Something similar occurs with the engagement construct items, EE3, "The teaching method used facilitated my active participation in the subject matter taught," and EE4, "The instructional approach used during the course interested me," again with $94 \%$ positive responses in chemistry majors versus $77 \%$ in non-chemistry majors.

In the components of attention, MA3, "The activities designed using this teaching method seem more attractive to me" and emotional engagement, CE1, "I demonstrated my interest and enthusiasm, as well as the use of a positive attitude during the course" a striking inversion of values is observed, with a higher positive percentage in non-chemistry majors ( $90 \%$ and $94 \%$, respectively) compared to chemistry majors ( $82 \%$ in both cases). The results of the responses are shown in Table 5.

Table 5. Comparison of the highest and lowest item values for chemical and non-chemical majors.

\begin{tabular}{ccccccc}
\hline \multicolumn{7}{c}{ Statistics Chemistry and Non-Chemistry Majors } \\
\hline Item & $\mathbf{N}$ & Component & Mean & Std. Dev. & $\begin{array}{c}\text { SA/A } \\
\text { Chemical }\end{array}$ & $\begin{array}{c}\text { SA/A } \\
\text { Non-Chemical }\end{array}$ \\
\hline MA2 & 2 & Attention & 4.58 & 0.58 & $100 \%$ & $94 \%$ \\
\hline CE3 & 23 & $\begin{array}{c}\text { Cognitive } \\
\text { Engagement }\end{array}$ & 4.54 & 0.65 & $100 \%$ & $87 \%$ \\
\hline CE2 & 22 & $\begin{array}{c}\text { Cognitive } \\
\text { Engagement }\end{array}$ & 4.54 & 0.62 & $94 \%$ & $94 \%$ \\
\hline MR1 & 5 & Relevance & 3.54 & 0.92 & $76 \%$ & $45 \%$ \\
\hline MR2 & 6 & Relevance & 3.69 & 0.80 & $76 \%$ & $65 \%$ \\
\hline MR4 & 8 & Relevance & 3.69 & 0.88 & $65 \%$ & $65 \%$ \\
\hline MC2 & 10 & Confidence & 3.23 & 1.04 & $41 \%$ & $42 \%$ \\
\hline
\end{tabular}

Among the items that obtained lower scores, MC2, "The exercises were too easy when using this teaching method," was the lowest of all with $41 \%$ positive values for chemistry majors and $42 \%$ for non-chemistry majors, followed by MR4, "The content of the teaching approach will be useful to me," with $65 \%$ in both cases. Regarding item MR1, "I could relate the content taught through this method to things I have thought about in my future life," a marked difference was observed, with $76 \%$ positive values for chemical majors in contrast to only $45 \%$ for non-chemical majors. The results are shown in Table 6.

\subsection{Analysis by Component (Q1028 +Q1029)}

Within the Motivation construct for Q1028 and Q1029, the Attention component has the highest average (4.41), followed closely by Satisfaction, with 4.32. A more marked difference is observed with the construct that obtained the lowest average of all, Relevance, with 3.73. The cognitive component was slightly higher in engagement, with a mean of 4.36, compared to the emotional component, whose mean was 4.31 .

\subsection{Component Analysis for Chemical and Non-Chemical Majors (Q1028 +Q1029)}

In a more specific analysis, the same trend is observed in students pursuing nonchemistry majors in global analysis, both in motivation and engagement. In students whose majors are focused on chemistry, this tendency is maintained in motivation; how- 
ever, a higher average is observed in emotional engagement (4.47) concerning cognitive engagement (4.46). The results are shown in Table 7.

Table 6. Results of the largest response differences between chemical and non-chemical majors.

\begin{tabular}{|c|c|c|c|c|c|c|c|}
\hline \multicolumn{8}{|c|}{ Statistical Difference between Chemistry and Non-Chemistry Majors } \\
\hline Item & $\mathbf{N}$ & Component & Mean & Std. Dev. & $\begin{array}{c}\text { SA/A } \\
\text { Chemical }\end{array}$ & $\begin{array}{c}\text { SA/A } \\
\text { Non-Chemical }\end{array}$ & $\begin{array}{c}\text { Difference } \\
\text { (Chemical-Non-Chemical) }\end{array}$ \\
\hline MR1 & 5 & Relevance & 3.54 & 0.92 & $76 \%$ & $45 \%$ & $31 \%$ \\
\hline MS4 & 16 & Satisfaction & 4.25 & 1.08 & $94 \%$ & $68 \%$ & $26 \%$ \\
\hline MS2 & 14 & Satisfaction & 4.35 & 0.91 & $94 \%$ & $74 \%$ & $20 \%$ \\
\hline EE3 & 19 & $\begin{array}{c}\text { Emotional } \\
\text { Engagement }\end{array}$ & 4.35 & 0.81 & $94 \%$ & $77 \%$ & $17 \%$ \\
\hline EE4 & 20 & $\begin{array}{c}\text { Emotional } \\
\text { Engagement }\end{array}$ & 4.35 & 0.76 & $94 \%$ & $77 \%$ & $17 \%$ \\
\hline MA3 & 3 & Attention & 4.42 & 0.71 & $82 \%$ & $90 \%$ & $-8 \%$ \\
\hline CE1 & 21 & $\begin{array}{c}\text { Cognitive } \\
\text { Engagement }\end{array}$ & 4.31 & 0.78 & $82 \%$ & $94 \%$ & $-11 \%$ \\
\hline
\end{tabular}

Table 7. Component results of the motivation and engagement constructs for chemistry and non-chemistry majors.

\begin{tabular}{ccccccccc}
\hline Construct & Component & Mean & Std. Dev. & $\alpha$ & $\begin{array}{c}\text { Mean } \\
\text { Chemical }\end{array}$ & $\begin{array}{c}\text { Std. Dev. } \\
\text { Chemical }\end{array}$ & $\begin{array}{c}\text { Mean } \\
\text { Non-Chemical }\end{array}$ & $\begin{array}{c}\text { Std. Dev. } \\
\text { Non-Chemical }\end{array}$ \\
\hline \multirow{3}{*}{ Motivation } & Relevance & 4.41 & 0.57 & 0.78 & 4.51 & 0.14 & 4.35 & 0.10 \\
\cline { 2 - 10 } & Satisfaction & 3.73 & 0.69 & 0.86 & 3.74 & 0.14 & 3.73 & 0.13 \\
\cline { 2 - 10 } & Satisfaction & 3.95 & 0.79 & 0.82 & 3.94 & 0.18 & 3.96 & 0.15 \\
\cline { 2 - 10 } & $\begin{array}{c}\text { Emotional } \\
\text { Engagement }\end{array}$ & 4.32 & 0.73 & 0.77 & 4.47 & 0.15 & 4.23 & 0.14 \\
\hline \multirow{2}{*}{ Engagement } & Emotional & 4.31 & 0.70 & 0.85 & 4.47 & 0.16 & 4.23 & 0.13 \\
\cline { 2 - 10 } & Cognitive & 4.36 & 0.61 & 0.73 & 4.46 & 0.16 & 4.31 & 0.11 \\
\hline
\end{tabular}

\subsection{Analysis by Course (Q1028 and Q1029)}

In general, a slightly higher average was observed in Q1029, with 4.28, compared to Q1028, with 4.06. The item MA2, "The teaching approach used (gamification) is eye-catching", had the highest positive values (95\% in Q1028 and 100\% in Q1029). MC2 had the lowest (50\% for Q1028 and 50\% for Q1029), respectively (see Table 8).

Table 8. Differences between Q1028 and Q1029 groups of items with highest and lowest scores.

\begin{tabular}{ccccccc}
\hline \multicolumn{7}{c}{ Statistics Q1028 and Q1029 } \\
\hline Item & $\mathbf{N}$ & Component & Mean & Std. Dev. & SA/A Q1028 & SA/A Q1029 \\
\hline MA2 & 2 & Attention & 4.45 & 0.596 & $95 \%$ & $100 \%$ \\
\hline MC2 & 10 & Confidence & 3.27 & 1.12 & $50 \%$ & $50 \%$ \\
\hline
\end{tabular}

The largest difference was observed in item MS4, "I learned surprising or unexpected things with this teaching method," with 93\% positive responses in Q1029, in contrast to only $55 \%$ positive responses in Q1028. A difference of 20\% was observed for items MS2, "It was a pleasure to learn chemistry through this pedagogy," and EE4, "The instructional approach used during the course interested me," with 93\% positive responses in Q1029 and 73\% in Q1028. In contrast, the largest difference observed (Q1028 having the highest value) was item CE1, "I demonstrated my interest and enthusiasm, as well as the use of a positive attitude during the 
course," with 95\% positive values in Q1028 in contrast to 79\% in Q1029. The results of the items are presented in Table 9.

Table 9. Results of the largest differences between responses for the Q1028 and Q1029 classes.

\begin{tabular}{cccccccc}
\hline Item & $\mathbf{N}$ & Component & Mean & Std. Dev. & $\begin{array}{c}\text { SA/A } \\
\text { Q1028 }\end{array}$ & $\begin{array}{c}\text { SA/A } \\
\text { Q1029 }\end{array}$ & $\begin{array}{c}\text { Difference } \\
\text { (SA/AQ1028-SA/AQ1029) }\end{array}$ \\
\hline CE1 & 21 & $\begin{array}{c}\text { Cognitive } \\
\text { Engagement }\end{array}$ & 4.32 & 0.716 & $95 \%$ & $79 \%$ & $17 \%$ \\
\hline MS2 & 14 & Satisfaction & 4.05 & 1.046 & $73 \%$ & $93 \%$ & $-20 \%$ \\
\hline MS4 & 16 & Satisfaction & 3.73 & 1.241 & $55 \%$ & $93 \%$ & $-38 \%$ \\
\hline
\end{tabular}

\section{Discussion}

It is known that the chemical concepts studied are abstract and challenging to learn for students in general, making it more complex to relate what they have seen to the real world in which they live [20]. This is further complicated when classes are developed in virtual environments, necessitated by the contingency caused by the COVID-19 pandemic [1]. Through this research, we presented the proposal we implemented with our students. We considered this proposal as innovative because it aimed to motivate student participation through short-, medium-, and long-term actions. To the best of our knowledge, although students' responses to these experiences were analyzed, there was little research found detailing how these activities could be developed and implemented in other environments.

Although the application of gamification activities has recently increased, driven predominantly by the need to promote online education, student participation is still low [41]. Moreover, these proposals were poorly planned due to the need to move from faceto-face to virtual environments in a short time. Therefore, this study aimed to contribute to the literature by providing an easy-to-implement gamification methodology for partial or fully remote environments. The novelty of this research is that it can be replicated without much effort by other teachers in other environments and the achievements serve as a basis for new possible designs. We also hope that the instrument used in this study will contribute to more research to measure the results of gamification activities on student motivation and engagement.

In this experience, we found that the students notably accepted the achievements. The three most motivating game elements were points for assignments, tickets earned through tokens, and bonuses for keeping the camera on. These game elements were related to autonomy, performance feedback, and competition, which were associated with intrinsic motivation and were valuable for determining whether the design used motivated the learner $[18,28]$. Nevertheless, it should be remarked that it was essential to remind students in several classes of the different ways to obtain achievements due to the short time of the subject, which meant that they did not get to earn all the possible bonuses. The main findings are discussed below:

- First, gamifying the homework activities placed on platforms, such as Mastering Chemistry, directly contributed to the students' learning effectiveness. It facilitated the completion of the exercises at home, immediate feedback, and, when necessary, the repetition of these activities. These findings coincided with what Trigueros et al. [14] stated, in that these types of activities made the tasks more attractive by empowering students to achieve their learning.

- Second, tickets obtained through participation could allow two very different and easily accessible achievements: decriminalizing and opening out-of-time assignments on the one hand and getting hints on exams on the other, so the predisposition of students who had to answer questions during class to get tokens was remarkable. A change that could be made regarding these permissions was to increase to four tokens per ticket; another was that in the multiple-choice question application (Wordwall), two questions equaled one token. In this way, students would not be able to collect as 
many tickets throughout the course, so they would value the feeling of having earned them even more and would think twice before using them.

- Third, at the beginning of the contingency, one of the first observations was that students preferred not to turn on their cameras during classes, which significantly minimized the possibility of reading their body language and facial expressions [52]. These non-verbal cues provided essential information for teachers to assess their performance in real-time and adjust on the spot if needed. Students themselves also benefit from seeing their peers and working collaboratively [47]. For this reason, professors encouraged students to turn on their video cameras, although the expected results were not always obtained. Adding the achievement of keeping the camera on wholly changed the dynamics because it meant that students had to tell the teacher privately if they needed to turn the camera off for a moment. At the end of the course, some mentioned that they were grateful for this format, as the class became more dynamic and interactive. This achievement showed us that gamification engaged students in the teaching process by motivating them to participate in the learning activities $[7,8,11]$.

- Finally, a critical element favoring gamification was continuous interaction. In this study, the students and teachers immediately knew of the progress made due to the continuous feedback provided through this technique. These results coincided with Oliva [53], in which this interaction encouraged the desired behavior. In this case, the students' achievements included, in addition to knowing their progress, collaborative attitudes and the recognition of others.

Concerning how much the achievements affected the final grades, we observed that the maximum score represented $4.5 \%$ of the student's grade, thus showing that the achievements generated incentives to redo the tasks and review the contents. Thus, they promoted delving into the subject, a small remuneration (in the form of a grade) that had a good payoff in learning due to the effort made.

From the survey, in order to know the students' perception of gamified classes, we observed that gamification as a teaching approach impressed them. They considered it relevant for the engagement in chemistry courses, possibly due to the difficulty of the subject. Additionally, we noted a greater class participation because of gamification. When students were consulted about their class experience, most commented that gamification increased their motivation and interest to participate in class. This finding was consistent with the results of consultees, where most participants indicated that the gamified course was more motivating and improved student engagement and participation [34]. On the other hand, we found that incorporating this teaching approach in a course did not affect the difficulty level of the exercises, nor does imparting content through this strategy make it more valuable and relevant. In addition, students mentioned that they did not necessarily focus on bonus activities, demonstrating their intrinsic motivation to study.

Slight differences were observed between the chemical majors and non-chemical majors. The most significant discrepancies were that students majoring in chemistry found it easier to relate the content taught through this method to their future professions; feeling more engaged and interested facilitated their active participation. Surprisingly, non-chemistry majors found that the activities designed through this teaching approach were more attractive, thus demonstrating their interest and positive attitude in the course.

As for the distinction by groups, a higher percentage of positive responses was observed in students from Q1029, in answer to the question that they learned more surprising things with gamification and found it pleasant and exciting to learn with this methodology. Q1028 students mainly highlighted their interest and enthusiasm during the course.

Finally, when comparing the pre-test and post-test results, there was an increase in the passing rate in the post-test once the students completed the gamified course, where students, especially from Q1029, obtained a higher percentage of passes. This result was consistent with other studies in which student grades improved with gamification 
activities [15]. However, further exploration of the impact of gamification on student learning outcomes is suggested.

\section{Conclusions}

This study tested a gamification experience with first-semester engineering students and reinforced their autonomy and engagement. Designing a gamification approach to work properly required a focused attention and empathy toward how students felt. There must be a balance between the amount of work and enjoyment and the system must be fair in rewarding points and permissions to students for achievements. This approach may not suit all learning styles; however, it can be enjoyable and educational for many.

Through this work, we proved that for this sample, the use of gamification strategies in class which recognized short-, medium-, and long-term achievements with bonuses stimulated the students, thus improving their motivation. The main findings in this proposal were:

- The students' comments from this first test were very positive and particularly receptive to achievements that had intended objectives, for example, keeping the camera on. The recognitions stimulated the students and generated a much more dynamic class.

- Another great success was the tokens, which encouraged student participation at all times. It was highly recommended to ask leading questions to make sure that everyone engaged with them. The most studious students were the first to raise their hands, so the best option was to select them as supervisors of the exercises to be solved in class.

- The least successful achievements were the mind maps, likely due to the students heavy workload in these and other subjects. Thus, adding extra activities for bonuses was not the best option in this educational model.

The results of this study are primarily contextual to our research. However, the simplicity of this gamified learning system merits further research, applying the method in other disciplines and verifying its effectiveness. It is recommended for future studies to apply this methodology in larger groups and other subjects, conducting this methodology online to continue improving students' performance in distance or blended courses. This is the time to continue leveraging and improving these strategies, even when returning to face-to-face classes. Soon, we intend to test this format in other disciplines and design specific software with this gamification system to examine students' perceptions using this technology.

Author Contributions: Conceptualization, G.M.C.; methodology, G.M.C. and M.P.C.; software, G.M.C. and M.P.C.; validation, G.M.C.; formal analysis, G.M.C. and M.P.C.; investigation, G.M.C.; resources, G.M.C.; writing — original draft preparation, G.M.C. and M.P.C.; writing-review and editing, G.M.C. and M.P.C. All authors have read and agreed to the published version of the manuscript.

Funding: The authors would like to acknowledge the financial support of NOVUS (Grant number: N20-161), Institute for the Future of Education, Tecnologico de Monterrey, Mexico, in the production of this work.

Institutional Review Board Statement: Not applicable.

Informed Consent Statement: Not applicable.

Data Availability Statement: Not applicable.

Acknowledgments: The authors would like to acknowledge the financial and technical support of the Writing Lab, Institute for the Future of Education, Tecnologico de Monterrey, Mexico, in the production of this paper.

Conflicts of Interest: The authors declare no conflict of interest. 


\section{References}

1. Nariman, D. Advances in Intelligent Systems and Computing. In Impact of the Interactive e-Learning Instructions on Effectiveness of a Programming Course, Complex, Intelligent and Software Intensive Systems; CISIS, 2020; Barolli, L., Poniszewska-Maranda, A., Enokido, T., Eds.; Springer: Cham, Switzerland, 2021; pp. 588-597.

2. Ramírez Montoya, M.S.; Valenzuela González, J.R. Innovación Educativa: Tendencias Globales de Investigación e Implicaciones Prácticas; Octaedro, S.L.: Barcelona, Spain, 2019.

3. Gómez-Zermeño, M.G.; Alemán de la Garza, L.; Portuguez-Castro, M.; Medina-Labrador, M. Innovación Educativa en Estudios Sobre el Desarrollo y uso de la Tecnología: Una Revisión Sistemática de Literatura. In Innovación EDUCATIVA: Tendencias Globales de Investigación e Implicaciones Prácticas; Ramírez Montoya, M.S., Valenzuela González, J.R., Eds.; Octaedro, S.L.: Barcelona, Spain, 2019; pp. 197-222.

4. Lozano-Rodríguez, A.; García-Vázquez, F.I.; Zubieta-Ramírez, C.; Lopez-Cruz, C.S. Competencies associated with Semestre i and its relationship to academic performance. High. Educ. Ski. Work-Based Learn 2020, 10, 387-399. [CrossRef]

5. Zahedi, L.; Batten, J.; Ross, M.; Potvin, G.; Damas, S.; Clarke, P.; Davis, D. Gamification in education: A mixed-methods study of gender on computer science students' academic performance and identity development. J. Comput. High. Educ. 2021, 33, 441-474. [CrossRef]

6. Attali, Y.; Arieli-Attali, M. Gamification in assessment: Do points affect test performance? Comput. Educ. 2015, 83, 57-63. [CrossRef]

7. Seaborn, K.; Fels, D.I. Gamification in theory and action: A survey. Int. J. Hum. Comput. Stud. 2015, 74, 14-31. [CrossRef]

8. Rodríguez Simon, A.I.; Regina López, S. Strategies of teaching in the mediated environments: Results of the experience of the virtual educational performance. Rev. Educ. Distancia 2017, 17, 55. [CrossRef]

9. Sailer, M.; Hense, J.U.; Mayr, S.K.; Mandl, H. How gamification motivates: An experimental study of the effects of specific game design elements on psychological need satisfaction. Comput. Human Behav. 2017, 69, 371-380. [CrossRef]

10. Alsawaier, R.S. The effect of gamification on motivation and engagement. Int. J. Inf. Learn. Technol. 2018, 35, 56-79. [CrossRef]

11. Koivisto, J.; Hamari, J. The rise of motivational information systems: A review of gamification research. Int. J. Inf. Manag. 2019, 45, 191-210. [CrossRef]

12. Domínguez, A.; Saenz-de-Navarrete, J.; de Marcos, L.; Fernández-Sanz, L.; Pagés, C.; Martínez-Herráiz, J.-J. Gamifying learning experiences: Practical implications and outcomes. Comput. Educ. 2013, 63, 380-392. [CrossRef]

13. Manzano-León, A.; Camacho-Lazarraga, P.; Guerrero, M.A.; Guerrero-Puerta, L.; Aguilar-Parra, J.M.; Trigueros, R.; Alias, A. Between Level Up and Game Over: A Systematic Literature Review of Gamification in Education. Sustainability 2021, $13,2247$. [CrossRef]

14. Trigueros, R.; Aguilar-Parra, J.M.; Lopez-Liria, R.; Cangas, A.J.; González, J.J.; Álvarez, J.F. The Role of Perception of Support in the Classroom on the Students' Motivation and Emotions: The Impact on Metacognition Strategies and Academic Performance in Math and English Classes. Front. Psychol. 2020, 10, 2794. [CrossRef] [PubMed]

15. Jurgelaitis, M.; Čeponienè, L.; Čeponis, J.; Drungilas, V. Implementing gamification in a university-level UML modeling course: A case study. Comput. Appl. Eng. Educ. 2019, 27, 332-343. [CrossRef]

16. Fontana, M.T. Gamification of ChemDraw during the COVID-19 Pandemic: Investigating How a Serious, Educational-Game Tournament (Molecule Madness) Impacts Student Wellness and Organic Chemistry Skills while Distance Learning. J. Chem. Educ. 2020, 97, 3358-3368. [CrossRef]

17. Ramírez Montoya, M.S.; Romero Rodríguez, L.M.; Castillo Abdul, B. Gamificación en MOOCS: Resultados de su Aplicación en la Innovación Universitaria; Octaedro, S.L.: Barcelona, Spain, 2021.

18. Hitchens, M.; Tulloch, R. A gamification design for the classroom. Interact. Technol. Smart Educ. 2018, 15, 28-45. [CrossRef]

19. Groh, F. Gamification: State of the Art Definition and Utilization. In Proceedings of the 4th Seminar on Research Trends in Media Informatics, Ulm, Germany; Ulm University: Ulm, Germany, 2012; pp. 39-46.

20. Osman, K.; Sukor, N.S. Conceptual Understanding in Secondary School Chemistry: A Discussion of the Difficulties Experienced by Students. Am. J. Appl. Sci. 2013, 10, 433-441. [CrossRef]

21. da Silva Júnior, J.N.; Zampieri, D.; de Mattos, M.C.; Duque, B.R.; Melo Leite Júnior, A.J.; Silva de Sousa, U.; do Nascimento, D.M.; Sousa Lima, M.A.; Monteiro, A.J. A Hybrid Board Game to Engage Students in Reviewing Organic Acids and Bases Concepts. J. Chem. Educ. 2020, 97, 3720-3726. [CrossRef]

22. Rincón Flores, E.G. Gamificación en ambientes masivos de innovación abierta en el área de sustentabilidad energética. Ph.D. Thesis, University of Salamanca, Salamanca, Spain, 2018.

23. Rincón-Flores, E.G.; Mena, J.; Montoya, M.S.R. Gamification: A new key for enhancing engagement in MOOCs on energy? Int. J. Interact. Des. Manuf. 2020, 14, 1379-1393. [CrossRef]

24. Tsai, C.-Y.; Lin, H.-S.; Liu, S.-C. The effect of pedagogical GAME model on students' PISA scientific competencies. J. Comput. Assisted Learn. 2020, 36, 359-369. [CrossRef]

25. Kyewski, E.; Krämer, N.C. To gamify or not to gamify? An experimental field study of the influence of badges on motivation, activity, and performance in an online learning course. Comput. Educ. 2018, 118, 25-37. [CrossRef]

26. Bandura, A. Going Global With Social Cognitive Theory: From Prospect to Paydirt. In The Rise of Applied Psychology: New Frontiers and Rewarding Careers; Donaldson, S., Berger, D., Pezdek, K., Eds.; Erlbaum: Mahwah, NJ, USA, 2006; pp. 53-79. 
27. Guajardo-Leal, B.E.; Gallardo Córdova, K.E. Engagement, motivation and persistence of xMOOC participants. Rev. Educ. Distancia 2021, 21, 440241. [CrossRef]

28. Deci, E.L.; Ryan, R.M. Self-Determination. In The Corsini Encyclopedia of Psychology; John Wiley \& Sons, Inc.: New York, NY, USA, 2010; pp. 1-2. [CrossRef]

29. Deci, E.L.; Ryan, R.M. Optimizing Students' Motivation in the Era of Testing and Pressure: A Self-Determination Theory Perspective. In Building Autonomous Learners: Perspectives from Research and Practice Using Self-Determination Theory; Liu, W.C., Wang, J.C.K., Ryan, R.M., Eds.; Springer: Singapore, 2016; pp. 9-29. [CrossRef]

30. Landers, R.; Callan, R. Casual Social Games as Serious Games: The Psychology of Gamification in Undergraduate Education and Employee Training. In Serious Games and Edutainment Applications; Springer: London, UK, 2011; pp. 399-423. [CrossRef]

31. Keller, J.M. Development and use of the ARCS model of instructional design. J. Instr. Dev. 1987, 10, 2-10. [CrossRef]

32. Keller, J.M. Motivational Design for Learning and Performance: The ARCS Model Approach; Springer: Tallahassee, Florida, USA, 2010. [CrossRef]

33. Esquivel Gámez, I. Los Modelos Tecno-Educativos, Revolucionando el Aprendizaje del Siglo XXI; Universidad Veracruzana: Veracruz, México, 2014.

34. Haruna, H.; Hu, X.; Chu, S.K.W.; Mellecker, R.R. Initial Validation of the MAKE Framework: A Comprehensive Instrument for Evaluating the Efficacy of Game-Based Learning and Gamification in Adolescent Sexual Health Literacy. Ann. Glob. Health 2019, 85, 1-7. [CrossRef]

35. Greene, K.M.; Lee, B.; Constance, N.; Hynes, K. Examining Youth and Program Predictors of Engagement in Out-of-School Time Programs. J. Youth Adolesc. 2013, 42, 1557-1572. [CrossRef] [PubMed]

36. Loureiro, S.M.C.; Bilro, R.G.; Angelino, F.J.d.A. Virtual reality and gamification in marketing higher education: A review and research agenda. Span. J. Mark.-ESIC 2020. ahead-of-print. [CrossRef]

37. Hartikainen, J.; Poikkeus, A.-M.; Haapala, E.A.; Sääkslahti, A.; Finni, T. Associations of Classroom Design and Classroom-Based Physical Activity with Behavioral and Emotional Engagement among Primary School Students. Sustainability 2021, $13,8116$. [CrossRef]

38. Fredricks, J.A.; Blumenfeld, P.C.; Paris, A.H. School Engagement: Potential of the Concept, State of the Evidence. Rev. Educ. Res. 2004, 74, 59-109. [CrossRef]

39. Özhan, Ş.Ç.; Kocadere, S.A. The Effects of Flow, Emotional Engagement, and Motivation on Success in a Gamified Online Learning Environment. J. Educ. Comput. Res. 2020, 57, 2006-2031. [CrossRef]

40. Nieto-Escamez, F.A.; Roldán-Tapia, M.D. Gamification as Online Teaching Strategy During COVID-19: A Mini-Review. Front. Psychol. 2021, 12, 1-9. [CrossRef]

41. Singh, P.; Duggal, K.; Gupta, L. Intrinsic and Extrinsic Motivation for Online Teaching in COVID-19: Applications, Issues, and Solution. In Emerging Technologies for Battling Covid-19. Studies in Systems, Decision and Control; Al-Turjman, F., Devi, A., Nayyar, A., Eds.; Springer: Cham, Switzerland, 2021; Volume 324, pp. 327-349. [CrossRef]

42. Raju, R.; Bhat, S.; Bhat, S.; D'Souza, R.; Singh, A. Effective Usage of Gamification Techniques to Boost Student Engagement. J. Eng. Educ. Transform. 2021, 34, 713-717. [CrossRef]

43. Hernández-Sampieri, R.; Mendoza Torres, C.P. Metodología de la Investigación: Las Rutas Cuantitativa, Cualitativa y Mixta, 1st ed.; McGraw-Hill: Ciudad de México, México, 2018.

44. Modelo Educativo Tec21; Instituto Tecnológico y de Estudios Superiores de Monterrey: Monterrey, Mexico, 2018.

45. Tro, N.J. Chemistry: A Molecular Approach; Pearson: Boston, MA, USA, 2017.

46. Johnson, L.F.; Smith, R.S.; Smythe, J.T.; Varon, R.K. Challenge-Based Learning: An Approach for Our Time; The New Media Consortium: Austin, Texas, USA, 2009.

47. Castelli, F.R.; Sarvary, M.A. Why students do not turn on their video cameras during online classes and an equitable and inclusive plan to encourage them to do so. Ecol. Evol. 2021, 11, 3565-3576. [CrossRef]

48. Aguilera Reyes, D. El Mapa Mental: Una Estrategia Cognitiva de Aprendizaje; Editorial Digital UNID: Estado de México, México, 2017.

49. Sivagami, V.G.; Balamurugan, M. Attitude towards learning difficulty in chemistry and academic achievement in chemistry among school students. Int. J. Modn. Res. Revs. 2019, 7, 26-32.

50. Linton, D.L.; Farmer, J.K.; Peterson, E. Is Peer Interaction Necessary for Optimal Active Learning? CBE Life Sci. Educ. 2014, 13, 243-252. [CrossRef] [PubMed]

51. Scager, K.; Boonstra, J.; Peeters, T.; Vulperhorst, J.; Wiegant, F. Collaborative Learning in Higher Education: Evoking Positive Interdependence. CBE Life Sci. Educ. 2016, 15, ar69. [CrossRef] [PubMed]

52. Tarc, P. Education post-'Covid-19': Re-visioning the face-to-face classroom. Curr. Issues Comp. Educ. 2020, 22, 121-124.

53. Oliva, H.A. La gamificación como estrategia metodológica en el contexto educativo universitario. Real. Reflex. 2017, 44, 29-47. [CrossRef] 